
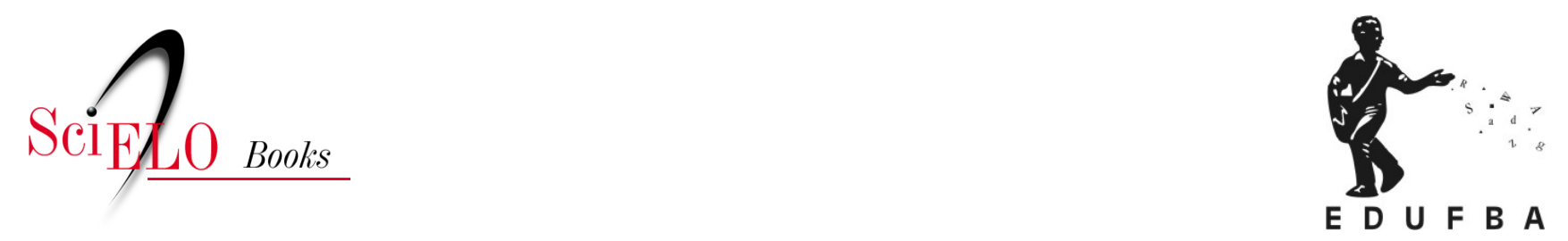

\title{
Capítulo 3 \\ Regulando o futuro subjetivo em direção à maternidade: a incessante construção de signos promotores
}

\author{
Vívian Volkmer Pontes
}

\section{SciELO Books / SciELO Livros / SciELO Libros}

PONTES, V.V. Regulando o futuro subjetivo em direção à maternidade: a incessante construção de signos promotores. In: Trajetórias interrompidas: perdas gestacionais, luto e reparação [online]. Salvador: EDUFBA, 2016, pp. 100-117. ISBN: 978-85-232-2009-9.

https://doi.org/10.7476/9788523220099.0005.

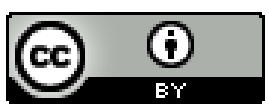

All the contents of this work, except where otherwise noted, is licensed under a Creative Commons Attribution 4.0 International license.

Todo o conteúdo deste trabalho, exceto quando houver ressalva, é publicado sob a licença Creative Commons Atribição $\underline{4.0}$. 
Capítulo 3

Regulando o futuro subjetivo em direção à maternidade: a incessante construção de signos promotores 


\section{Narrativa autobiográfica da trajetória reprodutiva de Joana no contexto público de saúde}

Eu pensava que podia esquecer um

dia, que eu podia esquecer tudo.

(Joana)

Joana possui trajetória reprodutiva marcada por cinco gestações e quatro perdas gestacionais - ocorridas, em geral, no último trimestre da gravidez. No momento em que foi realizada a entrevista, encontrava-se grávida de três meses. Em sua narrativa descreve a primeira gravidez, planejada e muito desejada pelo casal, ocorrida quando tinha entre 18 e 19 anos de idade. A gestação desenvolvia-se sem intercorrências, sendo Joana acompanhada, no pré-natal, por médicos de um serviço público na cidade do Salvador/BA. No entanto, aos seis meses de gravidez, um pequeno sangramento daria início a uma inesperada mudança de planos. O sangramento foi diagnosticado por um médico, em um primeiro momento, como algo "normal", mas, ao retornar para casa, o sangramento se intensificou, levando a uma nova busca por assistência médica. Desta vez, o diagnóstico médico levou-a a uma cesárea de emergência e ao nascimento prematuro de um bebê natimorto. A reação emocional de Joana ao saber da morte do bebê consistiu na não aceitação da perda e na busca desesperada pelo bebê perdido, sendo encaminhada para atendimento psicológico:

Só que quando ela (a médica) fez a cesárea, o bebê já 'tava' morto, aí simplesmente ela (a médica) falou comigo que tava morto, eu também aceitei na hora, 
anestesiada, tudo bem, quando foi no outro dia, veio o trauma, foi que veio aquele trauma de que eu queria porque queria aquele bebê... Tive um tipo... quase tive perda de memória... foi difícil demais... eu não estava aceitando, (não) dizia coisa com coisa, não 'tava' lembrando das coisas, só ficava chamando, queria só o bebê, só o bebê e elas me encaminharam para um psicólogo pra poder passar mais isso tudo, mas foi muito difícil... não conseguia me conformar de eu ter perdido, queria saber por que, não acreditava, ficava indo atrás do necrotério ver se tava lá, dizia que 'tava' lá, que tava vivo e tudo, entendeu, fiquei com trauma de bebê, não podia chegar ninguém de bebê junto de mim, nem também grávida, se chegava alguém grávida (perto) de mim já começava a me estressar, começava a ficar nervosa que eu não conseguia reagir por ver.

Apesar da intensa reação emocional após a perda, Joana e o parceiro realizaram o funeral do bebê, bem como o seu registro civil - condutas que não foram repetidas nas demais perdas gestacionais que, algum tempo depois, voltariam a ocorrer.

A fim de lançar algum entendimento à perda ocorrida, em diálogo com o parceiro, Joana constrói um significado pessoal para a causalidade da perda gestacional, ou seja, associa a perda a uma situação onde levou um “susto". Esse significado torna possível o planejamento de uma nova gestação; afinal, tendo conhecimento da causa do insucesso gestacional, tentaria evitar que esta situação voltasse a ocorrer. Assim, na segunda gestação, aos 23 anos de idade, Joana empenha-se na tentativa de controlar as incertezas futuras relativas à gravidez. Aumenta os cuidados com o próprio corpo, mantendo-se em repouso absoluto. No entanto, apesar dos seus esforços, aos oito meses de gestação dores abdominais a levam a percorrer alguns serviços da rede de saúde pública em busca de diagnóstico e tratamento. Mas, ao conseguir uma vaga em um serviço de emergência, Joana recebe a notícia de que o bebê já se encontrava natimorto, sendo comunicada de que seria necessário realizar um parto cesáreo. A reação emocional à notícia da perda gestacional consistiu em uma intensa aflição para Joana, o que levou a uma elevação da sua pressão arterial, e a um ato desesperado de trancar-se no banheiro da ala onde tinha sido internada, quando, então, o parto por via vaginal aconteceu espontaneamente. 
Após a vivência da perda, Joana relata ter decidido que não voltaria a engravidar novamente, apesar do intenso desejo do parceiro para ter um filho:

Não queria mais, não... É porque ele (parceiro) sempre quis... ter um filho. Eu também quero ter filho, só que a gente que passa pelo problema, pelo processo, acho que vai esfriando mais, só que renova quando a gente fica grávida, 'né'? Claro que renova. Mas, quando falava de gravidez comigo, eu pensava que eu podia esquecer um dia, eu podia esquecer tudo... fiquei com aquela psicose: "não quero mais saber de gravidez:

Porém, outro evento transformaria os planos de Joana. Afinal, a sua terceira gestação ocorreu quando fazia uso de contraceptivos. E a vivência dessa gestação consistiu em uma lembrança que, no momento da entrevista, Joana teve dificuldade para recordar. É muito provável que esse esquecimento se explique pelos momentos muito difíceis que cercaram essa gravidez, ocorrida aos 27 anos de idade: “A pior (gestação) que teve foi essa, eu acho que foi a pior que teve". Mais uma vez, a gestação seguia sem intercorrências. Estava realizando o acompanhamento pré-natal sem que nenhuma alteração fosse detectada. No entanto, no sétimo mês de gestação teve um intenso sangramento, o que a levou a buscar atendimento médico de emergência. A dificuldade de encontrar uma vaga em uma maternidade pública equipada com UTI neonatal - para o nascimento de um bebê prematuro - conduziu ao nascimento de mais um bebê natimorto. Porém, nesta circunstância, a vida da própria Joana foi colocada em risco, na medida em que houve complicações no seu estado geral de saúde. Uma séria infecção cujo tratamento medicamentoso parecia, a princípio, não fazer efeito, levou à percepção de risco à sua própria vida: "A terceira vez, que eu quase morro... foi... uma infecção alta, entendeu, grave mesmo,... eu quase morro também, porque eu não 'tava' conseguindo reagir aos medicamentos." Recorrer ao esquecimento pode ter constituído, deste modo, em um importante mecanismo psicológico para que ela pudesse seguir em frente e tentar novamente outra gestação.

Assim, na sua quarta gestação, aos 28 anos de idade, Joana resolve buscar um atendimento médico especializado em um ambulatório de 
abortamento de repetição de uma maternidade pública. Através desse serviço, obteve a primeira suspeita diagnóstica para a sua história de perdas gestacionais sucessivas, que se referia a um possível problema placentário. Além disso, foi-lhe oferecido um atendimento médico mais frequente, a fim de que se pudesse detectar qualquer alteração na sua gestação a tempo de alguma intervenção médica efetiva. Porém, apesar dessas mudanças introduzidas ao longo da sua quarta gestação, o trágico desfecho voltou a se repetir. E, assim, ao realizar um exame de ultrassom aos seis meses de gestação, o médico responsável constatou que havia alguma alteração nos batimentos cardíacos do bebê. Seguindo a orientação médica, Joana regressou à sua casa, a fim de aguardar alguns dias para repetir novamente o exame. Porém, o diagnóstico recebido neste segundo momento foi de óbito fetal.

Após a perda, a médica do ambulatório especializado em aborto de repetição recomendou que Joana realizasse uma investigação clínica acerca do que provocava as perdas gestacionais, através da realização de uma série de exames clínicos e laboratoriais. Mas Joana só regressaria à maternidade meses depois e novamente grávida. Nesse espaço de tempo, porém, outra experiência viria a marcar a sua trajetória reprodutiva e renovar as suas esperanças de conseguir levar esta gestação a termo e de vivenciar o nascimento de um filho vivo: uma cura espiritual na igreja evangélica que ela frequentava.

Joana relata que a cura foi proferida por um pastor de outra igreja e não pelo pastor habitual, que já a conhecia. Assim, durante o culto, esse pastor "de fora" convidou a todos os fiéis com algum tipo de problema para irem ao altar da igreja e orarem. Porém, Joana relata ter permanecido onde estava, estabelecendo nesse momento um diálogo com Deus, através da oração: "Olhe, Você sabe o meu problema qual é, eu não vou lá na frente, não. Se tiver de me curar, vai me curar aqui”. Ao término da oração, no entanto, o pastor vai até Joana e a convida para ir ao altar, quando, então, profere uma oração de cura: "Você está sendo curada agora, Deus está dando uma cura pra você agora... não é a cura que você queria, não é a cura do seu tempo, é a do tempo de Deus". Joana relata ter sentido intensa 
emoção durante essa experiência: "Eu chorava, eu chorei muito. Foi uma coisa que eu estava bem, que eu estava vivendo".

Esta experiência de cura levou o parceiro a incentivá-la a engravidar mais uma vez. O que de fato ocorreu, pela quinta vez, momento em que a entrevista com ela foi realizada. Joana relata estar mais esperançosa em conseguir controlar as possíveis intercorrências gestacionais, através do uso de algumas tecnologias médicas, como o uso de medicamentos e a possibilidade da realização de uma cerclagem - uma pequena intervenção cirúrgica com objetivo de manter o colo uterino fechado até o final da gestação, evitando um aborto tardio ou um parto prematuro:

Agora tem mais possibilidades... a gente vai fazer de tudo pra segurar esse agora... 'tô' tomando medicamento que eu nunca tomei de nenhuma (gravidez)... ela (a médica) disse que é um meio de ajudar a segurar a criança... eu fiz um exame de sangue, aí ela falou que era uma coisa que ia ser necessário costurar... no útero, pra fechar, pra não abrir antes do tempo, tudo isso ela falou comigo pra ser feito agora, nessa (gestação) aqui agora.

Apesar desses novos recursos e informações que dispõe para lidar com as incertezas futuras, Joana resolve não comprar o enxoval do bebê antes do seu nascimento. Assim, a esperança de, enfim, conseguir êxito na gestação atual convive com o medo e insegurança caracterizados por pensamentos negativos recorrentes e pela vigilância constante dos movimentos fetais, o que leva Joana a concluir acerca da necessidade de acompanhamento psicológico:

Por mais que a gente não queira colocar isso, mas a gente pensa negativo ..., porque você fica assim: 'Oh, já está mexendo (movimentos fetais sentidos na gestação)', aí quando passa, porque já está mexendo a gente quer que mexa toda hora, entendeu, quando não mexe já fica com aquela psicose: 'Oh, meu Deus, será que está bem? Será que não está bem? Será que eu devo falar com alguém?'... aí o que ele (parceiro) queria era isso, que tivesse uma pessoa assim que ouvisse a gente..., que faz muito bem pra gente, porque ele fala assim, que é bom porque vocês têm com quem conversar, têm com quem dizer o que sente, aí a gente falando o que sente a criança também está aliviada, 'né'? Aqui dentro está protegida, mas está aliviada também, por que o que adianta a gente guardar a angústia pra gente, 'né'? 


\section{As dinâmicas no âmbito do self: a tentativa de construir um sentido de continuidade}

O caso apresentado retrata a vivência de uma transição não normativa experienciada por uma mulher em direção à maternidade, desencadeada a partir da ocorrência inesperada de perdas gestacionais, que podem ser entendidas enquanto rupturas no curso do desenvolvimento, daquilo que era esperado ocorrer. A ruptura, em casos como este, aparece em diferentes níveis: no nível individual, no interior da mulher, com uma mudança brusca da identidade relacionada à maternidade que estava começando a ser construída e no nível micro, do seu papel social de mãe. De acordo com Zittoun (2004), os períodos de transição, ao longo do curso de vida, consistem em momentos onde certos eventos, por exemplo, a experiência de perdas gestacionais, colocam em risco determinados entendimentos e/ou identidades tidas como certas - como, por exemplo, a do tornar-se mãe. Esses eventos podem ser entendidos como rupturas no fluxo regular da experiência de alguém. Tais rupturas exigem processos de reposicionamento e podem solicitar novas aquisições, entendimentos e redefinições pessoais (Zittoun, 2004). Assim, pode-se dizer que, no início da trajetória reprodutiva de Joana, ela vivenciava uma situação aparentemente normativa, ou seja, um relacionamento estável com o parceiro, de modo que o desejo de maternidade seria uma maneira de dar continuidade aos estágios do curso de vida socialmente esperados, isto é, o de casar e o ter filhos.

Porém, a experiência das repetidas perdas gestacionais, com todo o sofrimento associado, coloca em questão esse desejo, o que leva Joana a aventar a possibilidade de não tentar mais ter o seu próprio filho. Afinal, a gravidez após a experiência de perdas gestacionais ganha a conotação de um símbolo multivalente, associado com significados e afetos tanto positivos, quanto negativos, criando um embaraço semiótico (semiotic rub) entre ideias e afetos concorrentes. (Abbey, 2004) Emerge, então, a ambivalência, entre o querer e o não querer tornar-se mãe, entre o continuar e o não continuar a tentar ter um filho biológico, entre a esperança 
de conseguir e a desesperança de não conseguir obter êxito gestacional. Com isto, o senso relativamente estável de ser mãe, que caracterizava o início da sua história reprodutiva, transforma-se ao longo do fluxo temporal, levando a uma ampliação do nível de incerteza em relação ao tornar-se mãe - incerteza que se intensifica com o surgimento de alguns conflitos e tensões entre as vozes de pessoas significativas da sua rede familiar e social.

Deste modo, quando Joana engravidou pela primeira vez, os signos de gravidez e maternidade suscitavam um nível mínimo ou leve de ambivalência - ou seja, consistiam em experiências que eram esperadas acontecer pessoal e socialmente, e significavam dar continuidade ao curso de vida. Porém, com a sucessão de perdas gestacionais, houve a emergência de ideias concorrentes, suscitando a construção de novos significados, muitas vezes irreconciliáveis (por exemplo, gestação = alegria e sofrimento, vida e morte, apoio familiar e ausência de apoio). Assim, a ambivalência se fortaleceu na medida em que a tensão entre esses significados irreconciliáveis aumentou. E, nesse sentido, a construção de significados tornou-se mais e mais errática, visto que Joana vai e vem com diferentes sugestões para o self (por exemplo, é adequado e esperado que eu me torne mãe; é inadequado que eu tente engravidar novamente e esperado que eu não insista; é adequado que eu tente engravidar novamente, apesar da ausência de apoio da família e amigos). (Abbey, 2004)

Assim, nos campos dinâmicos que caracterizam o self, onde se fazem presentes negociações, contradições e integrações (Hermans \& Hermans-Jansen, 2003), há a coexistência de perspectivas diferentes e, muitas vezes opostas, entre posições internas e externas do self. De um lado, alguns membros da sua família extensiva (em destaque, o seu próprio pai) posicionam-se contrariamente às novas tentativas de gestação, o que reflete não somente a dificuldade de suportar a sucessão de perdas e dor a elas associada, mas também a perspectiva futura de uma perda considerada ainda maior: a da própria mulher. A possibilidade desta perda é vislumbrada de dois modos: com a morte ou o enlouquecimento. Em 
relação à morte, a percepção de risco à vida de Joana foi coconstruída em decorrência das complicações à sua saúde após a terceira perda gestacional. Joana relata que a reação expressa por seu pai foi a de contrariedade e indignação: "a terceira vez que eu quase morro, meu pai ficou super aborrecido". Seguindo nessa direção, muitas outras vozes se manifestaram contrariamente às novas tentativas de gestação:

Tem muita gente que torce ao contrário, que acha que não era pra ter tentado... Teve uma senhora mesmo que é parente dele [parceiro], falou comigo assim: 'Oh, meu Deus, eu soube que você tinha perdido, achei bem pouco, Deus que me perdoe, bem pouco, ninguém mandou você engravidar de novo, não'. Então, apoio é uma coisa que a gente não tem.

Em relação ao segundo modo possível de perder a própria Joana, isto é, através da loucura, a narrativa dela faz referência às histórias contadas por familiares sobre uma parenta cujos três filhos nasceram mortos e, em decorrência disso, ela enlouqueceu. Assim, como resultado da dificuldade dos familiares de lidar com os eventos de perda, dos mais variados tipos, e da não concordância com o prosseguimento das tentativas de gestação realizadas pelo casal, há o afastamento dessas pessoas significativas e o isolamento de Joana, que se vê amparada apenas pelo parceiro, por Deus - através das suas orações -, e, em alguns momentos, por profissionais de saúde:

Eu não consigo nem entender o que passa na mente da minha familia... a falta de apoio deles é por não ter noção, pensa assim: 'acho que eu me afastando é melhor porque... não estou vendo o sofrimento dela. Não estou passando junto com ela o sofrimento'. Mas eu acho que é uma coisa que é o inverso, a gente tem que estar junto. Não só nas alegrias, tem que estar no momento de dor também.

Para Joana, o afastamento e a discordância dos familiares em relação à escolha do casal se devem ao fato deles serem "fracos do espírito", isto é, sem convicção religiosa, o que os impede de lhe oferecer qualquer suporte emocional (posição do Eu em destaque: Eu-filha). Assim, apesar do poder afetivo dessas vozes, Joana utiliza a estratégia de desqualificar esse outro e, com efeito, o que é dito por este, submetendo a posição do 
Eu-filha ao domínio de outras posições do eu, como o Eu-esposa, o Eu-mulher, e, em especial, o Eu-religiosa (Eu-evangélica). Afinal, ela encontra reconhecimento e empoderamento através dessa posição do Eu-religiosa, que se configura como uma posição poderosa, na medida em que a faz seguir na direção da maternidade e enfrentar a oposição de pessoas tão significativas. E, através dessas comunicações simbólicas, Joana negocia aspectos da sua identidade.

Na direção oposta a essas vozes, há a coexistência de uma perspectiva diferente, isto é, a voz do parceiro que se exprime em defesa pelo seu desejo de paternidade: "ele (o parceiro) sempre quis, ele tem um sonho, ter um filho". Esta voz, hierarquicamente dominante em relação às demais (e ligada à posição Eu-esposa), alia-se ao próprio desejo da mulher - que apesar de cada vez mais ambivalente - caminha na mesma direção, isto é, à da maternidade (Eu-mãe: posição do Eu potencial, futura). Desejo que para ela é compartilhado por todas as mulheres, ou seja, tem um caráter inerente à condição feminina, ao que é esperado socialmente e, até mesmo, biologicamente: "a tendência de todas as mulheres é ser (mãe)", (posição do Eu em destaque: Eu-mulher).

Vale ressaltar que tais relações dialógicas, estabelecidas ao longo da sua trajetória reprodutiva, encontram-se imersas em um contexto assistencial caracterizado por deficiências importantes no atendimento à gestante, como a fragmentação da assistência, o número insuficiente de vagas nos hospitais e a ausência de atendimento emergencial propriamente dito. Esse cenário, deste modo, configura-se em um importante obstáculo em direção à maternidade. Especialmente porque, no fluxo do tempo, há a coconstrução de significado com a rede familiar e social de que muitas das perdas ocorridas poderiam ter sido evitadas caso esse contexto fosse diferente.

Em vista desses acontecimentos, podemos pensar que, na trajetória reprodutiva de Joana emerge o que Sato, Hidaka e Fukuda (2009) denominam de ponto de bifurcação, isto é, um ponto de divergência influenciado pelas experiências do passado e possibilidades limitadas no futuro. Nesse ponto apresentam-se caminhos alternativos a serem seguidos pela 
pessoa, como engravidar novamente ou não engravidar, refletindo um alto nível de ambivalência. Nesse ponto de tensão, pelo menos dois poderes estão simultaneamente atuando: o poder da rede social próxima (orientação social) - marcado por sugestões sociais heterogêneas e até mesmo contraditórias, como as vozes dos familiares e a do parceiro -, e o poder sociocultural (direção social), no qual a maternidade é valorizada, consistindo em uma condição desejável à mulher. Frente a esses diferentes poderes sociais, que estão em conflito, Joana precisa tomar uma decisão que é construída a partir de um processo de síntese pessoal-cultural. Trata-se da "orientação pessoal sintetizada" (Synthesized Personal Orientation), que toma a forma de meta, de sonho. (Sato, Hidaka \& Fukuda, 2009; Sato \& Valsiner, 2010)

Uma questão fundamental torna-se, então, necessária: por que Joana escolhe persistir na tentativa de ter um filho, através da gestação, quando a sua experiência passada é marcada por tanta dor e sofrimento, por insucessos recorrentes e riscos à sua própria vida; enquanto o futuro é previsto de modo negativo, relacionado à possibilidade de outra perda gestacional, a riscos à sua própria vida e saúde mental? Por que continua a seguir nessa direção quando, ao longo do tempo, emerge um alto nível de ambivalência em relação ao seu próprio querer; quando as tensões e os conflitos entre significativas posições do Eu se intensificam; quando pessoas significativas se afastam e a desamparam; e, ainda, quando o contexto assistencial é percebido como responsável ou corresponsável por parte do seu sofrimento?

Para essas indagações não há uma resposta simples, fácil de ser alcançada. Porém, através da narrativa dessa mulher, alguns indícios parecem lançar luz no sentido do seu entendimento. Em primeiro lugar, deve-se ressaltar que o que está em jogo nesse caso envolve um signo hipergeneralizado - a maternidade - que se vincula a campos afetivos do tipo superior (nível mais alto de generalização) que regulam a totalidade da experiência vivida. A noção cultural de maternidade, deste modo, é carregada de valor, sendo socialmente promovida e pessoalmente internalizada. Configura-se em uma situação social e culturalmente regula- 
da, permeada por sugestões sociais presentes em ambientes humanos semioticamente organizados ou estruturados a partir da combinação de signos diversos, que possuem a função de guia social. O poder de tal situação/vivência social e seus significados hipergeneralizados guiam e organizam, desta forma, a conduta, o pensamento e os afetos humanos. (Valsiner, 2012)

$\mathrm{Na}$ atualidade e na realidade brasileira, a experiência do tornar-se mãe é marcada por uma valorização corporal da gravidez e pela persistência da maternidade como um valor fortemente associado à identidade feminina. A maternidade é concebida como uma experiência singular que transforma a mulher e agrega valores positivos na construção da sua identidade. A experiência corporal da maternidade, por sua vez, se articula com outra dimensão da identidade feminina, apoiada na ideia de autonomia e empoderamento social das mulheres. Assim, a maternidade contém elementos de afirmação da liberdade de escolha e autorrealização. (Vargas, 2006)

No caso analisado, esse signo é internalizado por Joana de modo muito particular, tornando-se parte da sua cultura pessoal. Afinal, ela faz uso da estratégia semiótica de intensificar os aspectos positivos do campo de significado do signo - que a orienta para o futuro - ao mesmo tempo em que ignora ou negligencia os aspectos associados a esse signo que lhe parecem mais incertos. Nesse sentido, o Eu-mãe aparece nesse contexto como uma posição do Eu projetada no futuro, sendo apropriada e entendida por Joana como a "coisa mais importante da vida", associada a emoções positivas como "alegria", "felicidade" e "renovação". Deste modo, esse signo é transformado ao longo do tempo, ganhando nuances de idealização, com a atribuição de muitos valores positivos:

Mãe é a coisa mais importante na vida, porque se a pessoa não tem mãe, não é nada... eu vejo a mãe como educadora, que vai instruir a pessoa, uma outra criatura, que vai ser assim, uma semente sua. Então, eu acho que ser mãe é tudo isso, tudo de bom. É uma coisa muito importante. 
Soma-se a isso o desejo de paternidade expresso pelo parceiro, outro signo hipergeneralizado que também funciona como um signo promotor em direção à busca do nascimento do filho. A paternidade aparece como um "sonho do parceiro", que "ele sempre quis", e que Joana percebe ter necessidade de realizar. Deste modo, parece haver certa aliança entre algumas posições do Eu altamente relevantes para o sistema do self de Joana, como o Eu-esposa (que deve dar um filho ao marido), o Eu-mulher (cuja tendência é ser mãe) e o Eu-mãe (posição do Eu futura, altamente valorizada). Posições que são alicerçadas por outra posição do Eu muito importante e dominante no sistema do self: o Eu-religiosa (Eu-evangélica).

A experiência de cura religiosa, deste modo, merece um destaque especial. Afinal, após a experiência de quatro perdas gestacionais, a coconstrução de risco à sua própria vida, a oposição e o desamparo da família extensiva, constituem circunscritores que poderiam inibir a ocorrência de uma nova gestação. Por este motivo, a escolha pela não maternidade foi tantas vezes aventada por Joana ao longo da sua trajetória reprodutiva. Porém, a experiência de cura religiosa, realizada por um "pastor novo", funcionou como um tipo de catalisador, diminuindo a ativação desses circunscritores e empoderando Joana em direção ao tornar-se mãe, bem como dando sustentação à voz do parceiro pelo seu desejo de paternidade.

Vale lembrar que a experiência de cura religiosa é antecedida por um diálogo com Deus, conhecedor do seu "problema”, mas realizada por um pastor que o desconhecia. E, como se Deus estivesse respondendo à sua prece, Joana é chamada pelo pastor para se engajar ativamente na oração de cura, em um espaço de experiência e sociabilidade. Afinal, trata-se de um ritual público, do qual ela foi pessoalmente convidada a participar. O "novo pastor", assim, funcionou como um agente catalítico, proporcionando-lhe um encontro com o sagrado, com o divino, em uma situação afetivamente orientada. Esta situação mobilizou o seu corpo "doente", bem como a sua emoção, levando Joana a chorar muito: "No momento... eu chorava, eu chorei muito. Foi uma coisa que eu 'tava' bem, eu 'tava' vivendo". A partir daí, um poderoso signo hipergeneralizado emergiu, passan- 
do a guiar os seus pensamentos, condutas e afetos - a "esperança": "Aí, quando foi em junho... eu parei o remédio (contraceptivo). Então, o que me deu a esperança maior é essa, 'né'? Porque quando Ele dá, ele garante".

Deste modo, a emergência da posição Eu-religiosa-curada-por-Deus oferece uma sustentação poderosa à aliança entre Eu-esposa, Eu-mulher e Eu-mãe, funcionando como uma posição promotora (Hermans \& Hermans-Konopka, 2010), isto é, posição que cria alguma ordem e direção na multiplicidade de posições do self, organizando, inovando e desenvolvendo o self ao longo do tempo. A partir dessa posição, é possível para Joana enfrentar as contradições e conflitos provenientes de vozes que vão no sentido contrário ao da maternidade.

Em detrimento a essas contradições e conflitos, os signos sugeridos pelos outros sociais (especialmente familiares) podem, então, ser rejeitados, desqualificados ou relegados ao esquecimento. E através desse processo de posicionamento e reposicionamento, marcado por tantas negociações no campo do self, há a possibilidade de continuidade de uma posição do Eu interna altamente relevante para o sistema do self, o Eu-mãe, bem como a instauração de um campo de significados mantenedores de um nível mínimo de ambivalência da condição experienciada.

Com isto, o futuro continua a ser vislumbrado atrelado à maternidade, envolvendo a persistência do comportamento de tentar engravidar, mesmo que outra perda gestacional venha a ocorrer:

Porque assim, se esse daqui ficar (gestação atual), eu vou esperar com paciência até o tempo dele nascer e tudo. Mas, também, se ele não vier, eu não vou desistir. Vou procurar um caminho novo, fazer o tratamento que tiver que fazer, fazer o que tiver que fazer pra eu ter ofilho e vou tentar novamente.

\section{O uso de recursos simbólicos e agência pessoal}

Com o propósito de dar sentido às experiências passadas, manejar suas interações com os outros e minimizar as incertezas futuras, Joana fez uso de uma série de recursos simbólicos, disponíveis no contexto cultu- 
ral no qual ela se insere. (Zittoun, Duveen, Gillespie, Ivinson, \& Psaltis, 2003) Isto ocorreu, especialmente, a partir da sua quarta gestação, após ter vivenciado não só a sua terceira perda gestacional, mas também ter construído a percepção de risco à sua própria vida. Deste modo, além dos cuidados com o próprio corpo, como manter-se em repouso, recorreu a outros recursos provenientes do campo médico e do campo religioso - duas instituições culturalmente associadas à capacidade de assegurar alguma certeza sobre a vida e o viver. A cada novo recurso simbólico introduzido e utilizado, renovava-se a esperança de um novo desfecho à sua história reprodutiva (expectativa de futuro), visto que um elemento diferente era introduzido em comparação com as experiências de perdas anteriores (memórias dos eventos passados). Isto é, aumentava-lhe a esperança de que o inesperado pudesse ocorrer.

Assim, quando Joana estava mais fragilizada, em uma situação de extrema vulnerabilidade - com a percepção de risco à sua vida e sem contar com apoio de sua própria família de origem -, ela vai buscar em outras esferas da experiência uma forma de dar sustentação, reconhecimento, legitimação à posição Eu-mãe. Busca, então, um empoderamento dessa posição que estava sendo ameaçada. E encontrou esse reconhecimento e suporte em outros sociais que são culturalmente reconhecidos e valorizados, como o médico, o pastor. Eles atuam empoderando o Eu-mãe de Joana, promovendo a coalizão interna de posições em torno dessa posição central no sistema do self.

Assim, durante a sua quarta gestação, recorreu a um serviço de saúde especializado em perdas gestacionais, sendo acompanhada com maior frequência por uma médica especialista: "a minha gravidez, eu achei que o meu bebê ia ter vida... porque tinha vezes que eu vinha duas vezes por semana na Dra. O... auscultando o bebê". Os signos "médico" mais "especialista", aliados ao uso mais frequente da "tecnologia" da ultrassonografia, levaram Joana a sentir-se mais segura, mais confiante acerca da possibilidade de sucesso reprodutivo.

No campo da medicina, a promessa de uma solução tecnológica para os mais diversos problemas de saúde pode aliviar a incerteza, tornando a 
vida mais previsível, controlável e dentro daquilo que é socialmente esperado, normativo. O saber médico e o seu poder, afirma Moulin (2008), se infiltrou no imaginário coletivo. Deste modo, os médicos configuram-se como um grupo social poderoso que impõem significados sobre o mundo por ordenar e organizar as coisas. Fronteiras simbólicas são, deste modo, construídas. No contexto das tecnologias reprodutivas, as fronteiras simbólico-culturais, bem como os processos de construção de identidade, atuam quando tais tecnologias são usadas. (Malin, 2003)

Além disso, a experiência de não maternidade involuntária leva muitas mulheres a se esforçar na direção de uma identidade normativa que é bastante valorizada social e culturalmente, ainda que negada por seus corpos materiais. Afinal, há um discurso sociocultural e até mesmo político sobre família, casamento e sexualidade que influencia uma tomada de decisão reprodutiva. Esse discurso enfatiza o imperativo cultural da maternidade, bem como a validação dos papéis de gênero através da parentalidade. (McDonell, 2011) Deste modo, a capacidade de procriação parece ser um importante referencial da identidade de gênero.

Porém, com a insistência do desfecho trágico, isto é, com a repetição da vivência de mais uma perda gestacional - mesmo com todo o aparato médico e tecnológico que lhe era acessível -, Joana recorre a outra poderosa instituição social: a religião - na busca incansável para superar as ambivalências, minimizar incertezas futuras e conseguir algum controle sobre sua própria vida, seguindo em direção da maternidade. Ela tem a experiência de cura espiritual na igreja que frequentava, realizada a partir da palavra de um outro significativo, "representante de Deus" o pastor -, legitimado pelo grupo de pessoas que assistia à cerimônia.

Paralelamente, outros recursos simbólicos, advindos do campo médico são também introduzidos a fim de auxiliá-la a lidar com a situação de incerteza: o uso de medicamento e a possibilidade de realizar uma intervenção cirúrgica no colo do útero, denominada cerclagem, para evitar o aborto tardio ou o parto prematuro. "Agora tem mais possibilidades... estou tomando medicamento que eu nunca tomei de nenhum (outra gestação anterior)... (é) um meio de ajudar a segurar a criança". 
Deste modo, Joana utiliza alguns elementos culturais, disponíveis no contexto em que se encontra inserida, e os utiliza para fazer algo - para agir sobre sua realidade pessoal, para mudar o desfecho da sua história reprodutiva, para alcançar um determinado posicionamento pessoal e social. E, mais do que isso, para empoderar a posição Eu-mãe no sistema do self, na medida em que busca reconhecimento e legitimação dessa posição no campo social - nas esferas da medicina e da religião. Ela, assim, constrói uma nova versão do próprio self. Nesse sentido, esses elementos tornam-se instrumentos - denominados por Zittoun (2004) como recursos simbólicos, para enfatizar o papel ativo da pessoa. Recursos simbólicos são, deste modo, elementos culturais mobilizados por uma pessoa em uma situação e utilizados a fim de fazer algo. (Zittoun, 2004) A escolha por alguém dos possíveis instrumentos para algum fim faz emergir a questão da agência pessoal.

A partir da perspectiva do construtivismo semiótico-cultural em psicologia, a pessoa é considerada a âncora dos processos discursivos que dinamicamente contribuem para a constituição da sua subjetividade, uma subjetividade que é suposta ser complexa, situada, contraditória e instável, bem como com capacidade de agência. Agência no que diz respeito à apropriação, rejeição, transformação ou modulação dos vários discursos, na escolha e uso dos elementos culturais e na construção de posições subjetivas. (Falmagne, 2004) Deste modo, a pessoa "agentivamente" constrói a sua própria identidade ao longo do tempo. (Abbey \& Falmagne, 2008) Entretanto, como enfatizam Abbey e Falmagne (2008), a agência possui uma flexibilidade limitada: ao mesmo tempo em que a pessoa é construída através desses processos que ocorrem nos níveis local e social, é também circunscrita por eles.

A Figura 3 ilustra os principais aspectos analisados da trajetória reprodutiva de Joana, com ênfase para as estratégias semióticas para a construção de continuidade e manutenção da posição Eu-mãe após a quarta perda gestacional. 


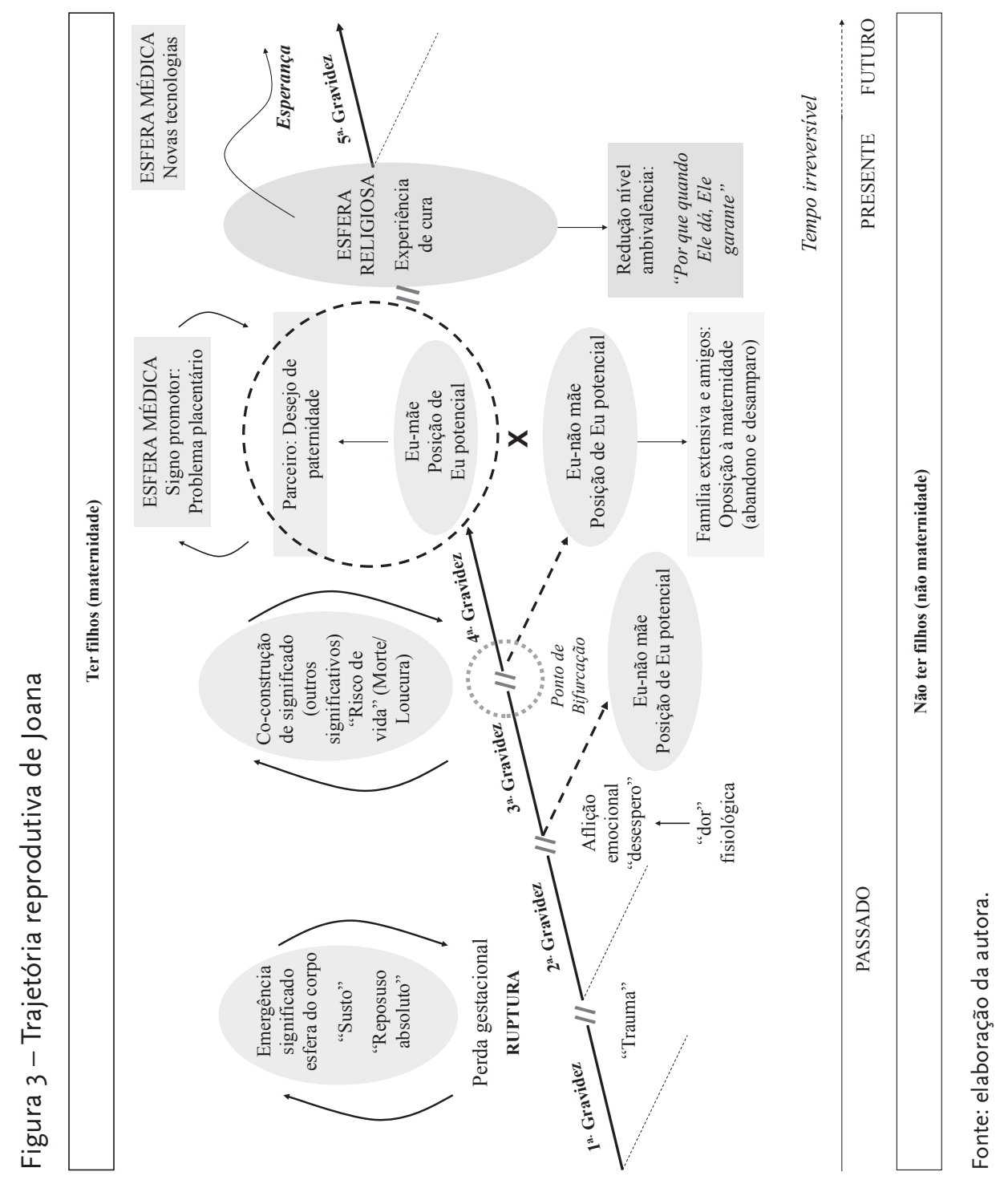

